\title{
CONVERS[AÇÃO] ENTRE A EDUCAÇÃO AMBIENTAL E A FILOSOFIA: PARA PENSAR O CONSUMO E O DESCARTE DE ELETRÔNICOS
}

\author{
Isabel Cristina Dalmoro1; Vanessa Hernandez Caporlingua²; Vanessa dos Santos \\ Moura $^{3}$
}

\section{RESUMO}

O texto que segue apresenta os resultados de uma Ação interdisciplinar pensada a partir das contribuições da Educação Ambiental em diálogo direto com a Filosofia, com ênfase na área Política de Hannah Arendt. O tema central e fio condutor da Ação foi o consumo e descarte de produtos eletrônicos. $O$ objetivo geral compreendeu a análise da questão socioambiental em torno desse tipo de produto, identificando o papel da Filosofia na Ação de Educação Ambiental. Elegeu-se como estratégia de ensino a aplicação de duas oficinas envolvendo trinta estudantes de um curso pré-vestibular de uma ONG de educação popular em Porto Alegre - RS. Salienta-se que a Ação realizada se apresentou como uma estratégia de ensino potente para o encontro dos dois saberes envolvidos.

Palavras-chave: Educação Ambiental; Filosofia; Resíduos Eletrônicos.

\section{CONVERS[ACTION] BETWEEN ENVIRONMENTAL EDUCATION AND PHILOSOPHY: TO THINK THE CONSUMPTION AND DISPOSAL OF ELECTRONICS}

\begin{abstract}
The following text presents the results after an interdisciplinary Action thought from the contributions of Environmental Education in direct dialogue with Philosophy, emphasizing in Hannah Arendt's Political area. The central theme and conducting wire of this Action was consumption and disposal of electronic products. The general objective comprehended the analysis of the socioenvironmental issue around this type of product, identifying the role of Philosophy in the Environmental Education Action. It was chosen as teaching strategy the application of two workshops involving thirty students of a college preparatory course of an NGO of popular education in Porto Alegre - RS. It's emphasized that the accomplished Action was presented as a powerful
\end{abstract}

1 Mestranda no PPG Educação em Ciências: Química da Vida e Saúde (PPGEC/UFRGS). Bolsista CAPES. E-mail: isadalmoro.filosofia@gmail.com.

2 Doutora em Educação Ambiental. Professora do Programa de Pós-graduação em Educação Ambiental (PPGEA/FURG). Professora da Faculdade de Direito (FADIR/FURG). Líder do Grupo de Pesquisa Direito e Educação Ambiental (GPDEA/CNPQ). E-mail: vcaporlingua@gmail.com.

3 Doutoranda em Educação Ambiental (FURG). E-mail: vanessamoura@yahoo.com.br. 
teaching strategy to the meeting of these two knowledges involved.

Keywords: Environmental Education; Philosophy; Eletronic Waste.

\section{Primeiras notas: o encontro da Educação Ambiental e a Filosofia}

O presente relato apresenta um projeto de Ação ${ }^{4}$ que compreendeu a elaboração e a aplicação de uma Ação interdisciplinar pensada a partir das contribuições da Educação Ambiental em diálogo direto com a Filosofia, com destaque para a área Política de Hannah Arendt. A mencionada Ação se justificou por duas razões, quais sejam: 1) a necessidade de encontrar estratégias de ensino que promovessem a convergência entre a Educação Ambiental e a Filosofia e 2) a premência de analisar referenciais teóricos que pudessem fornecer o embasamento para o encontro acontecer. Para contar como os resultados da Ação proposta sobrevieram, o presente texto conta com quatro seções, iniciando com essa que elenca os objetivos e o tema gerador tanto da Educação Ambiental como da Filosofia, os quais permitiram pensar a trajetória que promoveu o encontro entre as duas áreas, bem como a definição do caminho a ser seguido: a Ação por meio de oficinas.

A proposta teve como questão motivadora buscar saber de que modo o público alvo da Ação de Educação Ambiental, a saber, trinta estudantes de um curso pré-vestibular ${ }^{5}$ de Porto Alegre (RS), identificados como consumidores de produtos eletrônicos, em específico do aparelho celular, se relaciona com esse tipo de objeto no que diz respeito ao consumo e descarte dos resíduos gerados. O objetivo geral da Ação consistiu em analisar a questão socioambiental em torno do consumo e descarte de eletrônicos, identificando o papel da Filosofia na ação de Educação Ambiental. Para mais, elegeram-se os seguintes objetivos específicos: (1) reconhecer a questão dos resíduos sólidos como resultado da ação humana, (2) distinguir os conceitos de consumo e obsolescência programada e livre, pertinentes à sociedade contemporânea, e (3) identificar o conceito de sociedade de massas, gerado pela alienação diante dos bens de consumo.

\footnotetext{
4 Elaborado e executado no Curso de Especialização em Educação Ambiental - Lato Sensu, da Universidade Federal do Rio Grande (UAB/FURG).

${ }^{5}$ Organização Não-Governamental para a Educação Popular (ONGEP): http://www.ongep.com/ Acesso em 15/08/18.
} 
A fim de alcançar os objetivos propostos, adotou-se como estratégia de ensino a ser seguida a aplicação de duas oficinas, sob o título de Jogar Fora? Oficinas de Educação Ambiental e Filosofia ${ }^{6}$, contando cada uma delas com cinquenta minutos de duração, em dois períodos distintos e subsequentes das aulas $^{7}$ de Filosofia do referido curso, no turno da manhã. O conceito da Filosofia escolhido para ser estudado foi o de sociedade de massas, abrangendo o conceito de sociedade de consumo, tal como sustentado por Arendt (2012). A questão do consumo e descarte de resíduos eletrônicos, abarcando o tema da obsolescência programada, foram os pontos escolhidos para serem debatidos na Ação de Educação Ambiental, tendo em vista o volume desse tipo de resíduos gerado anualmente ${ }^{8}$.

A segunda seção do texto apresenta a inspiração que motivou a convers[Ação], na qual se evocam os marcos teóricos que a fundamentaram e que possibilitaram o diálogo entre a Filosofia e a Educação Ambiental. $\mathrm{Na}$ referida seção apresenta-se a definição para o termo interdisciplinaridade adotado para a Ação executada, bem como a corrente da Educação Ambiental na qual essa se situa e a noção de meio ambiente eleita para a realização do projeto e das oficinas. Na terceira seção do texto discorre-se a respeito dos resultados alcançados pela convergência das duas oficinas envolvendo a Educação Ambiental e a Filosofia. Para tanto, são apreciados os materiais produzidos pelos estudantes durante a realização da Ação a fim de avaliar a eficiência da proposta. A quarta seção do texto apresenta considerações acerca da prosa efetuada, apontando algumas reflexões sobre a convers[Ação].

Adianta-se que os diálogos assentados entre a Educação Ambiental e a Filosofia apresentados nesse relato não esgotam as possibilidades de pensar o encontro entre os dois saberes. Entende-se que esses diálogos se mostram como um possível caminho para identificar e enfrentar coletivamente as

\footnotetext{
${ }^{6}$ As notas sobre o planejamento da Ação com caráter interdisciplinar efetivada por meio de duas oficinas, bem como os roteiros que serviram como guia para cada um dos dois encontros realizados, encontram-se disponíveis nos anais do IX Encontro e Diálogos com a Educação Ambiental, promovido pela Universidade do Rio Grande - FURG (DALMORO; CAPORLINGUA; MOURA, 2018, p. 411-420).

${ }^{7}$ Agradecemos aos professores Graziella Alcântara Mazzei, Mateus da Silva Pereira e Elisa Lemos Vigna, bem como aos estudantes da ONGEP pela acolhida, espaço e tempo concedidos para que essa Ação pudesse ser realizada.

${ }^{8}$ Segundo Cerati (2017), no ano de 2018 os latino-americanos deverão jogar no lixo cerca de 4.800 toneladas de resíduos eletrônicos (e-waste), o que equivale a $10 \%$ do total global.
} 
questões que permeiam tanto a sociedade atual como a crise ambiental vigente.

\section{Inspir[Ação] para a convers[Ação]: marcos teóricos}

Para alcançar os objetivos propostos pela Ação, buscou-se, primeiramente, os fundamentos teóricos que dessem o embasamento para que a possível conversa entre a Educação Ambiental e a Filosofia pudesse acontecer. Para tanto, por se tratar de uma Ação construída de modo interdisciplinar, considerou-se a seguinte referência para 0 termo interdisciplinaridade: "o envolvimento não apenas ${ }^{9}$ de dois saberes, mas de um saber com ${ }^{10}$ outro saber, ou dos saberes entre si, numa sorte de complementaridade, de cumplicidade solidária, em função da realidade estudada e conhecida" (COIMBRA, 2000, p. 56).

Além disso, como suporte para a Ação realizada, adotou-se como pressuposto teórico a posição que sustenta que a Educação Ambiental é capaz de suscitar a ação conscientizadora entre o eu e o outro, envolvendo, para tal, a "capacidade crítica, diálogo, assimilação de diferentes saberes, e a transformação ativa da realidade e das condições de vida" (LOUREIRO, 2012, p. 34). Nesse sentido, entende-se que a "Educação Ambiental é uma práxis"1 educativa e social que tem por finalidade a construção de valores, conceitos, habilidades e atitudes que possibilitem o entendimento da realidade da vida" [...] (LOUREIRO, 2011, p. 73). Ainda, conforme menciona o autor suprarreferido, a Educação Ambiental, por ser portadora de um caráter político, passa a ser um "espaço pedagógico de exercício da cidadania", com a recomendação de se assumir a cidadania "como algo que se constrói permanentemente [...], se constitui ao dar significado ao pertencimento do indivíduo a uma sociedade, em cada fase histórica" (LOUREIRO, 2011, p. 79). De tal modo, essa é a noção de cidadania que se levou em conta no planejamento e na execução da Ação. Também, encontrou-se no mesmo texto do autor o convite para levar a Educação Ambiental para o cotidiano de instâncias organizadas (entidades assistenciais e filantrópicas, ONGs e outras).

\footnotetext{
9 Grifo do autor.

10 Grifo do autor.

11 Grifo do autor.
} 
Neste convite encontrou-se os elementos que corroboraram a Ação ter sido realizada na Organização Não-Governamental para a Educação Popular (ONGEP), dado que as qualidades elencadas por ele ilustram em grande parte a mencionada organização, a saber:

[...] é fundamental associarmos processos educativos formais às demais atividades sociais de luta pela qualidade de vida e

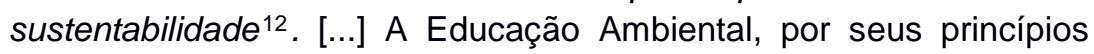
integradores e de promoção de qualidade de vida, pode constituir o elo entre o entendimento do ambiente escolar como totalidade que inclui a comunidade em que a escola se insere e a luta dos profissionais do ensino pela democratização das relações de poder na instituição educativa (educação inclusiva e não sexista, direção colegiada, condições materiais adequadas para 0 trabalho pedagógico ${ }^{13}$, etc.). (LOUREIRO, 2011, p. 97-98).

Para a elaboração e execução da Ação, optou-se pela corrente da Educação Ambiental Crítica, caracterizada como aquela que concebe o problema ambiental associado ao conflito social de tal modo que impulsiona a inserção política do indivíduo no processo de transformação da realidade socioambiental. Nessa perspectiva, a Educação Ambiental é capaz de promover o acesso a subsídios que possibilitam o questionamento das estruturas sociais vigentes, permitindo a emancipação do sujeito e levando-o a pensar e agir coletivamente. Ou seja, a Educação Ambiental Crítica tem por objetivo "promover ambientes educativos de mobilização de processos de intervenção sobre a realidade e seus problemas socioambientais" (GUIMARÃES, 2004, p. 30).

Em vista disso, a Educação Ambiental diz respeito à instrumentalização do educando para que aconteça a inserção política dele no processo de transformação da realidade socioambiental, dada sob o incentivo de projetos que promovam a interface entre várias áreas do conhecimento na busca de diferentes saberes. Por esse ângulo, a Ação realizada por oportunizar a aproximação dos dois saberes pode ser considerada como uma via de mão dupla, uma vez que se encontrou a possibilidade de trazer a Filosofia para contribuir com a temática da Educação Ambiental, bem como, por meio da questão socioambiental escolhida para motivar a Ação, oportunizou-se à

12 Grifo nosso.
13 Grifo nosso. 
Filosofia a reflexão crítica sobre os seus próprios conceitos.

Isso posto, foi no âmbito da Política, fundamentada na concepção da Filosofia crítica de Arendt (2012), que se inseriu a Ação de Educação Ambiental, com caráter interdisciplinar. Por conta disso, considerou-se relevante abordar o conceito de sociedade de massas como resultante de uma sociedade de consumo ${ }^{14}$. Na descrição para o conceito de sociedade de massas, Arendt (2012, p. 439) sustenta que essa pode, potencialmente, existir "em qualquer país e constituem a maioria das pessoas neutras e politicamente indiferentes, que nunca se filiam a um partido político e raramente exercem seu poder de voto". Tendo sua origem na burguesia, a massa faz parte da sociedade competitiva de consumo e está alienada da sua própria condição. Tomou-se, assim, como referencial a análise arendtiana sobre o tema, transpondo para um modelo de sociedade mantida pela conformidade ante aos bens de consumo, caracterizada pela indiferença e apatia política, para pensar sobre o consumo e o descarte de produtos eletrônicos. Além do mais, a indiferença desse modelo de sociedade em relação às questões que envolvem a pluralidade ${ }^{15}$ é capaz de gerar os regimes totalitários.

Ainda no âmbito do conceito de sociedade de massas arendtiano, relacionando com o consumo desnecessário, pode-se afirmar que num estilo de vida em que os produtos consumidos não estão ligados a uma função ou necessidade específica a "sociedade contemporânea é uma grande sociedade de massas, onde reinam a produção em série e a distribuição massiva de produtos e serviços" (ZACARIAS, 2000, p. 37-38). Em vista da Ação envolver o debate sobre a questão do consumo excessivo e diante do aprofundamento dos impactos ambientais assinalados pelas relações sociais capitalistas, quando promovem a expansão deste entre a população, trouxe-se à tona a seguinte reflexão: "É um equívoco relacionar as causas da crise ambiental apenas aos padrões de produção e consumo da sociedade contemporânea [...]

\footnotetext{
${ }^{14}$ No sentido de consumo compulsório, entendido como aquele que vai além das necessidades humanas, tratando-se do consumo em demasia provocado pelo forte apelo das propagandas presentes na mídia.

${ }^{15} \mathrm{O}$ conceito de pluralidade é apresentado na obra de Arendt A Condição Humana (CH, 1958). Trata-se, segundo a autora, "[...] da condição humana da pluralidade, ao fato de que os homens, e não o Homem, vivem na Terra e habitam o mundo" (ARENDT, 2013a, p. 8).
} 
tais manifestações são exclusivamente das relações capitalistas" (ZACARIAS, 2009, p. 138).

Para tratar da questão da geração e descarte de resíduos sólidos, consideraram-se oportunas as considerações de Layrargues (2011) ao abordar o tema dos catadores nos processos de reciclagem - assunto que deu início à Ação de Educação Ambiental. Segundo o autor, a reciclagem, tal como acontece nos dias atuais, disfarça o fenômeno da alienação, uma vez que se trata também "do consumismo como fator de degradação ambiental e engrenagem dos mecanismos sociais de acumulação de capital e concentração de renda [...]" (LAYRARGUES, 2011, p. 215). O autor defende, ainda, que a vida útil dos objetos é cada vez mais curta, havendo uma "união entre a obsolescência planejada e a criação de demandas artificiais no capitalismo" (idem, p. 211), afirmando que o consumismo é também considerado como responsável por uma série de problemas ambientais e por conta disso "não pode mais ser compreendido unicamente como sinônimo de felicidade" (idem p. 189). Reitera: [...] "esse é o problema do consumismo, uma questão eminentemente cultural, relacionada à incessante insatisfação com a função primeira dos objetos em si” (LAYRARGUES, 2011, p. 190). Além disso, ao discutir os padrões de consumo praticados pelo primeiro mundo e pelas elites do terceiro mundo, de modo que se constituem como a "força propulsora do esgotamento ambiental", emerge a possibilidade da transformação do consumidor em um verdadeiro cidadão consciente (idem).

Para mais, ao abordar a questão socioambiental naquilo que é característico da Filosofia, ou seja, na reflexão crítica sobre conceitos que lhe são pertinentes tais como consumo, obsolescência e sociedade de massas, oportunizou-se aos envolvidos na Ação um debate que fosse além da mera informação sobre os temas escolhidos para o estudo, repensando as posturas alienantes numa sociedade consumista, de modo que:

[...] a Educação Ambiental pode ser interpretada como uma etapa num processo maior, que talvez ainda nem sequer tenha começado. Uma etapa muito importante na medida em que abre frentes de discussão, onde a Filosofia ${ }^{16}$ se vê convocada a se pronunciar diante de novas questões (FARIAS, 2008, p. 4).

Ressalta-se que no contexto da Ação de Educação Ambiental, levou-se

${ }^{16}$ Grifo nosso. 
em conta que ao debater a questão do consumo excessivo e a postura alienante diante da crise socioambiental vigente pode-se viabilizar a transformação de realidades por meio da relação dos envolvidos com o meio ambiente. Para tanto, adotou-se o seguinte significado para meio ambiente: "um lugar determinado e/ou percebido onde estão em relações dinâmicas e em constante interação os aspectos naturais e sociais" (REIGOTA, 2006, p. 21). Ou seja, o meio ambiente é o espaço onde se dá a relação entre nuances, ora verde, ora cinza - o lado verde e bonito da natureza, vivo em todas as espécies que nela se encontram e o lado cinza da cidade do qual nós, de algum modo e em algum momento, somos integrantes. Dito isso, passa-se para a terceira seção deste artigo que tem como meta discorrer sobre os resultados atingidos na Ação que promoveu a conversa entre a Educação Ambiental e a Filosofia, ilustrando com os momentos das oficinas em que se entende ter ocorrido o encontro dos referenciais teóricos acima mencionados. Para a apreciação dos resultados obtidos contou-se com o apoio de Lüdke e André (1986), uma vez que se lançou mão dos instrumentos de análise citados pelas autoras que são a observação e os respectivos registros dessa, bem como se fez uso da análise de conteúdo, no que tange ao material elaborado pelos estudantes.

\section{Convers[Ação]: a convergência dos encontros}

A metodologia utilizada para a Ação, assim como para a coleta de dados, foi a da técnica de pesquisa qualitativa da observação participante, em que "o pesquisador e os objetivos do estudo são revelados ao grupo pesquisado desde o início", como apresentam Lüdke e André (1986, p. 29). Por conta disso, a análise do material elaborado pelos estudantes, tal como as anotações registradas, seguiu pela mesma concepção das autoras, ou seja, o respectivo material foi compreendido por meio da técnica de análise de material qualitativo denominada análise de conteúdo. Adianta-se que se realizou a "investigação de conteúdo simbólico" na temática proposta, na qual se buscou os aspectos políticos e filosóficos das produções elaboradas, por meio das palavras e das sentenças utilizadas, tal como descrevem Lüdke e André (1986, p. 41).

Para pôr em prática a Ação que visava a promoção do encontro entre a 
Educação Ambiental e a Filosofia, na concepção arendtiana, bem como possibilitar a efetivação dos objetivos específicos da proposta elaborada, a estratégia de ensino adotada foi a realização de duas oficinas, sendo a primeira delas a que fez acontecer a aproximação entre os dois saberes. $\mathrm{Na}$ segunda oficina, como complementação à primeira, tratou-se do conceito de consumo, aproveitando o momento para examinar a distinção que ocorre entre os conceitos de obsolescência programada e livre, como também se analisou o conceito de sociedade de massas, gerado pela alienação diante dos bens de consumo.

Desse modo, passa-se para a exposição dos momentos da primeira das duas oficinas aplicadas, realizada no turno da manhã, com duração de cinquenta minutos. Inicialmente, os estudantes em duplas/trios elaboraram um pequeno texto abarcando os conceitos que abrangem tanto a disciplina envolvida como a temática proposta, a saber: Educação Ambiental, consumo, sociedade de consumo e Filosofia. Para orientar os estudantes na elaboração do texto, sugeriu-se que respondessem a seguinte questão: "Qual a possível relação entre os conceitos de Educação Ambiental, consumo, sociedade de consumo e Filosofia?". Dentre as repostas produzidas, pode-se aferir que os estudantes estabeleceram possíveis relações entre a Educação Ambiental e a Filosofia. Nesse sentido, foi a característica da reflexão crítica da Filosofia que se mostrou como um suporte para pensar a questão ambiental, indicando a Educação Ambiental como auxiliar para o problema do consumo.

O segundo momento da Ação consistiu na exibição de trecho do documentário $O$ homem do saco ${ }^{17}$, quando os estudantes tiveram a oportunidade de observar e refletir sobre a questão dos resíduos sólidos como resultado da ação humana. Após a exibição de trecho do referido documentário, passou-se para uma conversa acerca daquilo que foi assistido, momento em que os estudantes elencaram conceitos além daqueles da atividade inicial acima citada, tais como: profissão de catador: trabalho, reconhecimento, falta de oportunidade; pirâmide social, capitalismo, poder público - sistema. Comentou-se com os estudantes sobre estarmos todos inseridos dentro de um sistema que envolve o capitalismo, ao mesmo tempo

17 O Homem do saco. Produção: BLACKOUT Produções Digitais. São Paulo, 2017. Duração: 58:03 minutos. Disponível em: https://www.youtube.com/watch? $v=\mathrm{j} 0 \mathrm{w}$ CaFv2eg Acesso em $15 / 08 / 18$. 
que somos todos, de algum modo, integrantes da sociedade de massas. Outros pontos também foram citados pelos estudantes, como: objetos encontrados pelos catadores, a indiferença e a falta de incomodação das pessoas em torno dos problemas ambientais, conforme termos utilizados por eles. Para o termo incomodação [a falta de] adotou-se o termo apatia, possibilitando trazer o pensamento de Arendt (2012) para abordar a questão da alienação diante da sociedade de consumo, demonstrando a aproximação com o referencial teórico.

A segunda oficina, realizada no turno da manhã e com duração de cinquenta minutos, teve como propósito passar da conversa à Ação, ou seja, distinguir os conceitos de consumo e obsolescência programada e livre, pertinentes à sociedade contemporânea, e identificar o conceito de sociedade de massas, gerado pela alienação diante dos bens de consumo. A oficina, então, iniciou com a retomada dos conceitos levantados pelos estudantes durante a conversa ocorrida após a exibição de trecho do documentário $O$ homem do saco (acima referenciado), numa apresentação em data show, onde os respectivos slides traziam temas como consumo e descarte de eletrônicos, obsolescência programada e livre, anúncios de vendas de aparelhos celulares circulados na mídia. A conversa com os estudantes desenrolou-se também pela perspectiva da reciclagem, abordando a quantidade de resíduos eletrônicos gerados anualmente no mundo. Percebeu-se a necessidade de se entender, num primeiro momento, o consumo excessivo como um problema para depois buscar soluções para esse. Nesse ponto, chamou-se a atenção dos estudantes para o que Layrargues (2011, p. 215) denominou como cinismo da reciclagem, uma vez que o estímulo para a reciclagem dissimula o problema do consumo excessivo e, por conseguinte, não apresenta os efeitos necessários e urgentes à "melhoria ambiental" (idem). Utilizando o exemplo do aparelho celular para melhor entender a distinção entre os conceitos de obsolescência programada e livre, pertinentes à sociedade contemporânea, passou-se para as indagações ${ }^{18}$ acerca da maneira como os estudantes lidam com o referido produto (ver Quadro). Nesse momento, comentou-se sobre os danos ambientais que o descarte incorreto desses aparelhos pode causar ao

${ }^{18}$ Solicitou-se auxílio de uma estudante para a anotação das respostas, uma vez que essa atividade ocorreu oralmente, sob a forma de conversa dirigida. 
meio ambiente, apresentando alternativas para o encaminhamento desse tipo de resíduo.

Quadro: Perguntas e Respostas

\begin{tabular}{|l|l|}
\hline \multicolumn{1}{|c|}{ Perguntas } & \multicolumn{1}{c|}{ Respostas } \\
\hline Quem (não) possui celular? Por quê? & $\begin{array}{l}\text { Todos os estudantes presentes responderam } \\
\text { que possuíam celular. A maioria respondeu que } \\
\text { foi por volta dos dez anos de idade que } \\
\text { ganharam o primeiro aparelho e u utilizam para } \\
\text { acessar redes sociais e falar com a família. }\end{array}$ \\
\hline $\begin{array}{l}\text { Quantos aparelhos já possuiu? } \\
\text { Por que trocou? }\end{array}$ & $\begin{array}{l}\text { A maioria dos estudantes mencionou já ter tido } \\
\text { entre dois e três celulares. Sobre o motivo da } \\
\text { troca de aparelhos, os estudantes comentaram } \\
\text { que foi por estrago do aparelho ou por estética } \\
\text { (aparência) }\end{array}$ \\
\hline $\begin{array}{l}\text { Qual } \\
\text { substituído? }\end{array}$ & $\begin{array}{l}\text { Os estudantes disseram que costumam doar ou } \\
\text { vender os aparelhos antigos. Cerca de cinco } \\
\text { estudantes disseram que não põem no lixo } \\
\text { porque é errado, mas não souberam explicar a } \\
\text { razão de considerarem errado descartar o } \\
\text { celular no lixo comum. }\end{array}$ \\
\hline
\end{tabular}

Fonte: Arquivo próprio.

A partir das respostas dadas é possível afirmar que: 1) o uso do aparelho celular faz parte do cotidiano dos estudantes envolvidos na Ação desde a infância, servindo para acesso às redes sociais; 2) a troca dos respectivos aparelhos acontece por conta de estragos ocorridos e pela busca de um aparelho mais moderno e esteticamente melhor - ilustrando o tema da obsolescência programada e livre que integra a Ação; e 3) o descarte acontece por meio de venda ou doação do aparelho antigo. Contudo, observou-se que permaneceram no âmbito dos conceitos de certo e errado ao fornecerem as respostas sobre os danos ocasionados ao meio ambiente com o descarte incorreto dos aparelhos celulares.

Para mais, no que tange às respostas geradas pelos estudantes, é possível inferir que o tema que motivou a questão norteadora dessa Ação se mostrou capaz de gerar as condições para o começo da conversa entre a Educação Ambiental e a Filosofia. Por conta das respostas dadas para a pergunta que buscava saber qual o destino dos resíduos eletrônicos gerados, em que aludiram ao conceito de que é errado o descarte destes no lixo comum, sem apontar boas razões para isso, encontrou-se a possibilidade de uma nova abordagem filosófica para a questão dos resíduos eletrônicos (e sólidos em

19 Nesse momento, a partir das respostas dos estudantes, foi feita a distinção entre os conceitos de obsolescência programada e livre. 
geral), a saber, no campo da ética ambiental ${ }^{20}$.

$\mathrm{Na}$ sequência da Ação, buscou-se fazer a relação dos conceitos estudados até o momento, e que dizem respeito ao consumo e descarte de resíduos eletrônicos, com os conceitos pertinentes à Filosofia Política de Arendt, tal como o de obsolescência programada, que a autora critica em seu texto A Condição Humana (2013a, p. 314), como sendo um dos motivos do chamado "milagre econômico" alemão pós-guerra ${ }^{21}$, no qual a autora aborda a apropriação e a expropriação de objetos. Além disso, tratou-se de caracterizar o conceito de sociedade de consumo, também conforme a teoria arendtiana, abordando as noções de sociedade de massas, de indiferença e apatia política, conforme sustentado por Arendt (2012, p. 439-441). Ainda, sobre a sociedade de consumo, apresentou-se a concepção arendtiana de que o referido modelo de sociedade envolve a afirmação de que esse pode ser considerado uma ameaça para o mundo uma vez que, na atitude de consumir, o indivíduo da sociedade de consumo "não sabe cuidar do mundo e das coisas e condena à ruína tudo o que toca" (ARENDT, 2013b, p. 264).

Após, passou-se para a atividade final da oficina que consistiu na reescrita sobre a relação da Educação Ambiental e a Filosofia, procurando conectar alguns conceitos abordados tanto sobre os resíduos eletrônicos e sociedade de consumo com os apresentados sobre a sociedade de massas, segundo a concepção arendtiana. Um dos pontos relevantes diz respeito ao questionamento de alguns estudantes sobre os motivos pelos quais esse tipo de tema, referindo-se à temática da Educação Ambiental, não ser tão abordada nas escolas e tampouco as informações acerca da Logística Reversa ${ }^{22}$ (que

\footnotetext{
20 Por ética ambiental entende-se a área da Filosofia que estuda a relação do ser humano com o meio ambiente, envolvendo o valor e o status moral desta convivência com o não-humano. Nesse sentido, a ética ambiental é capaz de tratar com: i) a preservação da biodiversidade como um objetivo ético; ii) as preocupações com o ambiente construído e as políticas de pobreza, dentre outros pontos. Definição extraída e adaptada de Stanford Encyclopedia of Philosophy. Disponível em: < https://plato.stanford.edu/entries/ethics-environmental/ Acesso em 15/08/18.

${ }^{21}$ Conforme Arendt: o exemplo alemão demonstra claramente que, nas condições modernas, a expropriação de pessoas, a destruição de objetos e a devastação das cidades converteram-se num estímulo radical para um processo de mera recuperação, mas de acúmulo de riqueza ainda mais rápido e eficaz [...] (2013a, p. 314).

22 Sobre a Logística Reversa, comentou-se com os estudantes que se trata de um dos instrumentos para a aplicação da responsabilidade compartilhada pelo ciclo de vida dos produtos, em que o setor empresarial deve viabilizar a coleta e a restituição dos resíduos sólidos para reaproveitamento em seu ciclo ou em outros ciclos produtivos, ou outra destinação
} 
também foi abordada durante a apresentação dos slides na Oficina Dois), não chegarem ao alcance de todos. Por conta destes comentários, foi feita a alusão ao exercício da cidadania em que ocorre a busca pelo direito à informação e que remete aos interesses econômicos que estão na base dessa falta de informação. Nesse momento, percebeu-se a relação do tema proposto e discutido com o pensamento de Loureiro (2011, p. 76), uma vez que a Ação se constituiu em um "espaço de exercício da cidadania", entendida como algo em construção permanente. Além disso, de acordo com o que foi conversado com os estudantes, entende-se que houve a promoção para o desenvolvimento desses com o intuito de se tornarem o "cidadão consciente responsável", defendido por Layrargues (2011, p. 221).

Nos textos que integram o material para a análise da Ação realizada foi possível constatar, por meio das palavras e das sentenças utilizadas, a compreensão dos estudantes de que todos nós fazemos parte da sociedade de massas, dado que estamos inseridos na dinâmica da sociedade de consumo que abarca a apropriação e a desapropriação de objetos, numa espécie de alienação ante os bens de consumo. Ainda, percebeu-se nesses textos a assimilação dos estudantes do conceito de indiferença, segundo a visão arendtiana, e a relação desse com o tema do cinismo da reciclagem, na perspectiva de Layrargues (2011), quando mencionam a não preocupação com os impactos ambientais que os resíduos eletrônicos podem causar ao meio ambiente, considerando isso desde a produção inicial desse tipo de produto, e a adoção da reciclagem como uma alternativa para amenizar o consumo excessivo. A característica da alienação da sociedade de massas e o consumo compulsório incentivado pela mídia foram temas relacionados com o problema do capitalismo e também abordados pelos estudantes em seus textos. Nesse contexto percebeu-se a correspondência dos escritos com o pensamento de Zacarias (2009), em que a crise ambiental é considerada uma consequência das relações capitalistas que permeiam a sociedade contemporânea. Além disso, notou-se que os estudantes ao se perceberem como parte integrante da sociedade de consumo, elencaram comportamentos que fazem parte de um ciclo que abrange o uso, o descarte incorreto e a nova aquisição de produtos, e 
que constituem as etapas características da dinâmica da apropriação e expropriação de objetos. Essa percepção pode ser acolhida como uma instrumentalização do educando, sendo capaz de ocasionar a transformação de uma realidade socioambiental, num processo de intervenção sobre essa realidade, atingindo um dos pontos que remete aos objetivos da Educação Ambiental Crítica, tal como defendida por Guimarães (2004, p. 30).

Diante do exposto, nos argumentos apresentados pelos estudantes, é possível perceber a apreensão desses no que se refere aos elementos que caracterizam a sociedade de massas, como a sociedade de consumo, alienação, indiferença e apatia política, segundo a Filosofia arendtiana, estabelecendo a possível relação desses elementos com as noções pertinentes à Educação Ambiental de cariz crítico.

\section{Últimas notas: algumas consider[Ações] sobre a prosa}

No percurso desse texto buscou-se apresentar os resultados alcançados na concretização do projeto de Ação de Educação Ambiental planejado em diálogo direto com a Filosofia, na concepção Política de Hannah Arendt. De acordo com o que foi aqui exposto, pode-se inferir que a Ação tal como proposta e realizada apresenta-se como uma estratégia de ensino potente para o encontro dos dois saberes envolvidos. Ressalta-se que o documentário escolhido para iniciar a Ação, demonstrou ser um rico recurso didático a ser utilizado como instrumento sensibilizador para motivar uma análise da realidade vigente, tendo em vista o retorno fornecido pelos inseridos na Ação, ilustrado pelos debates ocorridos e pelos textos elaborados. Além do mais, o referencial teórico adotado para a promoção desse encontro forneceu o embasamento necessário para tanto, dado o diálogo estabelecido e mencionado ao longo desse texto.

No que tange à Filosofia, em específico ao conceito de sociedade de massas arendtiano, considera-se que a Ação proporcionou uma atualização do pensamento de Arendt, uma vez que se encontrou na aproximação dos saberes a oportunidade de uma abordagem em relação ao consumo de modo a repensar hábitos pertinentes ao consumismo num modelo de sociedade em que todos nos encontramos envolvidos. Em relação à Educação Ambiental, 
notou-se a possibilidade de ir além da mera informação dos danos causados pelo descarte incorreto de resíduos eletrônicos no meio ambiente.

Nesse sentido, de acordo com os resultados atingidos pela Ação realizada em que se promoveu, a partir de um olhar sobre o comportamento da sociedade em geral, a compreensão de que estamos atrelados à dinâmica que caracteriza a sociedade de consumo, concernente à sociedade de massas, entende-se que essa proposta pode vir a ser um elemento que possibilita uma interpelação aos envolvidos para a mudança positiva dessa realidade.

Chama-se a atenção para os resultados alcançados, uma vez que neles se evidencia que a proposta como pensada não esgota as possibilidades de trazer conceitos inerentes da Filosofia para atuar com a Educação Ambiental. Logo, considera-se válido pensar sobre conceitos e ações a fim de incentivar a discussão, a sensibilização e a reflexão para outras Ações de Educação Ambiental com caráter interdisciplinar, em que se busque ir além da mera informação acerca das questões pertinentes à crise socioambiental.

\section{Referências}

ARENDT, Hannah. Origens do Totalitarismo. Tradução de Roberto Raposo. São Paulo: Companhia das Letras, 2012.

ARENDT, Hannah. A Condição Humana. Tradução de Roberto Raposo. Revisão Técnica e Apresentação de Adriano Correia. 11aㅡ ed. Rio de Janeiro: Forense Universitária, 2013a.

ARENDT, Hannah. A crise na educação. In: ARENDT, Hannah. Entre o passado e o futuro. Tradução de Mauro W. Barbosa. 7ạ ed. São Paulo: Perspectiva, 2013b, p. $221-247$.

BRASIL. Ministério do Meio Ambiente. Lei 12.305, de 02 de agosto de 2010. Institui a Política Nacional dos Resíduos Sólidos. Brasília, DF: Brasília, 2010.

CERATI, Mariana Kaipper. Lixo eletrônico: um mercado com potencial milionário. Jornal El país Brasil, Brasília, 18 fev. 2017. Política. Disponível em https://brasil.elpais.com/brasil/2017/02/18/politica/1487418470 101918.html

Acesso em 15/08/18.

COIMBRA, José de Ávila Aguiar. Considerações sobre a Interdisciplinaridade. In: PHILIPI Arlindo Jr; TUCCI, Carlos E. Morelli; HOGAN, Daniel Joseph; NAVEGANTES, Raul (Orgs.). Interdisciplinaridade em Ciências Ambientais. São Paulo: SIGNUS Editora, 2000, p. 52-70. 
DALMORO, Isabel Cristina; CAPORLINGUA, Vanessa Hernandez; MOURA, Vanessa dos Santos. Notas sobre o planejamento de uma proposta de ação interdisciplinar por meio de oficinas. In: Encontros e Diálogos com a Educação Ambiental, 9, Rio Grande. Anais do IX Encontro e Diálogos com a Educação Ambiental, Rio Grande, FURG, 2018, p. 411-420. Disponível em https://drive.google.com/file/d/0B6rmD 1H4no0NS1wMFVJWUIVTmlxWG1vV3 VjMzNZalpPNIRn/view?ts=5ab3b487 Acesso em 15/08/18.

FARIAS, André Brayner de. Filosofia e ecologia: para uma educação ambiental crítica. Congresso Internacional de Filosofia: ideias e debates de cidadania. Caxias do Sul/RS, 2008. Disponível em: https://www.ucs.br/ucs/tplCongressoFilosofia/extensao/agenda/eventos/cd 60/c omunicacoes cientificas/apresentacao/papel filosofia/andre.pdf Acesso em 15/08/18.

GUIMARÃES, Mauro. Educação Ambiental Crítica. In: LAYRARGUES, Philippe Pomier (Coord.). Identidades da Educação Ambiental Brasileira. Brasília: MMA, 2004, p. 25-34.

LAYRARGUES, Philippe Pomier. O cinismo da reciclagem: o significado ideológico da reciclagem da lata de alumínio e suas implicações para a Educação Ambiental. In: LOUREIRO, Carlos Frederico; LAYRARGUES, Philippe Pomier; CASTRO, Ronaldo Souza de (Orgs.). Educação Ambiental: repensando o espaço da cidadania. São Paulo: Cortez Editora, 2011, p. 185225.

LOUREIRO, Carlos Frederico Bernardo. Trajetória e Fundamentos da Educação Ambiental. 4ª ed. São Paulo: Cortez Editora, 2012.

LOUREIRO, Carlos Frederico Bernardo. Educação Ambiental e movimentos sociais na construção da cidadania ecológica e planetária. In: LOUREIRO, Carlos Frederico Bernardo; LAYRARGUES, Philippe Pomier; CASTRO Ronaldo Souza de (Orgs.). Educação Ambiental: repensando o espaço da cidadania. São Paulo: Cortez Editora, 2011, p. 73-103.

LÜDKE, Menga; ANDRÉ, Marli. E.D.A. Capítulo 3. Métodos de Coleta e dados: observação, entrevista e análise documental. In: Educação: abordagens qualitativas. São Paulo: EPU, $\overline{1986, \text { p. }}$ 25-44.

REIGOTA, Marcos. O que é a Educação Ambiental. São Paulo: Brasiliense, 2006.

ZACARIAS, Rachel. Sociedade de consumo: ideologia do consumo e as iniquidades socioambientais dos atuais padrões de produção e consumo. In: LOUREIRO, Carlos.

Frederico Bernardo; LAYRARGUES, Philippe Pomier; CASTRO, Ronaldo Souza de (Orgs.). Repensar a educação ambiental: um olhar crítico. São Paulo: Cortez Editora, 2009, p. 119-139.

ZACARIAS, Rachel. Consumo, Lixo e Educação ambiental: uma abordagem crítica. Juiz de Fora: FEME, 2000. 